\title{
Characterization and assessment of volatile organic compounds (VOCs) emissions from typical industries
}

\author{
WANG HaiLin ${ }^{1}$, NIE Lie $^{2}$, LI Jing ${ }^{2}$, WANG YuFei ${ }^{1}$, WANG Gang ${ }^{1}$, WANG JunHui ${ }^{1}$ \& \\ HAO ZhengPing ${ }^{*}$ \\ ${ }^{1}$ Department of Environmental Nano-materials, Research Center for Eco-Environmental Sciences, Chinese Academy of Sciences, Beijing 100085, \\ China; \\ ${ }^{2}$ Department of Air Pollution Prevention and Control, Beijing Municipal Research Institute of Environmental Protection, Beijing 100037, China
}

Received March 30, 2012; accepted May 4, 2012

\begin{abstract}
VOCs play an increasingly important role in affecting air quality and threatening human health in China in recent years, where industry activities show a significant contribution to VOCs emission. In this article we report our long term study of industrial VOCs emissions of six major industries (vehicle manufacturing, printing, equipment coating, electronic manufacturing, furniture manufacturing and bio-pharming) on the aspects of emission characteristics, environmental impact and health risk assessment, and control challenge analysis with the purpose to obtain in-depth understanding of industry VOCs emissions and offer some original basements for national control and management of industry VOCs emissions. This study shows that all these industries give middle or low emission with total VOCs concentration less than $1000 \mathrm{mg} / \mathrm{m}^{3}$ at each exhaust pipe. Benzenes, esters, alcohols, ketones, alkanes, chloroalkanes and alkenes were detected as the major emission components and the most frequently monitored VOCs were benzenes, which varied obviously with different processes and industries. The environmental impact assessments indicate that vehicle manufacturing and benzenes should be prior controlled with the purpose to reduce air pollution. While, health risk assessments suggest that furniture manufacturing and chloroalkanes should be firstly controlled. Control analysis indicates that developing technologies with low cost and high efficiency and establishing and completing specific industry emission standards/regulations are the two key issues in VOCs emission management at present stage.
\end{abstract}

VOCs, typical industries, emission characteristics, assessment, control analysis

Citation: Wang H L, Nie L, Li J, et al. Characterization and assessment of volatile organic compounds (VOCs) emissions from typical industries. Chin Sci Bull, 2013, 58: 724-730, doi: 10.1007/s11434-012-5345-2

As for the definition of VOCs, WHO (World Health Organization), EU (European Union), US EPA (Environmental Protection Agency), ISO (International Organization for Standardization) and other organizations give various definitions based on different consideration. However, in China VOCs usually refer to a series of organic chemical compounds which have significant vapor pressures and are easy to volatilize in the atmosphere [1-3]. VOCs have different sources, which could be generally divided into natural sources and anthropogenic sources. Natural sources include vegetation emission, agricultural respiration and forest fire etc. Anthropogenic sources mainly refer to vehicle exhaust

*Corresponding author (email: zpinghao@rcees.ac.cn) emission, oil gas evaporation, industry emission, oil refining, storage and transportation, waste material disposal and others. Generally, VOCs emission amounts from these two sources are quite different. Natural sources release much more VOCs than anthropogenic sources globally [4,5]. However, in China the amounts of VOCs emission from anthropogenic and natural sources are at the same level [6,7]. In regional scale, VOCs emission amounts from anthropogenic activities are much higher than those from natural sources [7-9]. It is calculated that industry emission (related to most kinds of industrial processes or activities including use of organic solvents) is the largest anthropogenic source of VOCs in China at present [10,11].

According to our survey, most VOCs from industry 
emission are not treated effectively and released into atmosphere directly, which already have been proved to be harmful to public health. For example, chlorobenzene is commonly used as a solvent for adhesives, rubber, paint, and fiber-swelling agent in textile processes, occupational studies have indicated that acute and chronic exposure to chlorobenzene could cause distinct symptoms, such as headaches and irritation of the mucosa of the upper respiratory tract and eyes [12-14]. Diethylhexyl phthalate (DEHP) is commonly used in the production of medical devices as plasticizer, and studies have found that unusual lung disorders like respiratory distress, pathological changes resembling hyaline membrane disease are observed in three preterm infants artificially ventilated with PVC respiratory tubes [15]. According to the ref. [16], benzene, toluene and xylene could result in serious neurosis and cardiac diseases for workers exposed to those pollutants for long-term. In addition, VOCs characterized by their photochemical activity could undergo a series of photochemical reaction to form the secondary organic aerosol, which is one of the major components of airborne fine particles. Some studies show that the dominated precursors of smog in big cities are VOCs $[17,18]$. Related research indicates that ozone formation in Guangzhou urban area is greatly affected by the anthropogenic VOCs and photochemical smog pollution in the Pear River Delta caused by ground-level ozone is becoming worse [19].

Due to the obvious impacts on atmosphere and human health, the General Office of the State Council (GOSC) issued an important circular, which firstly suggested VOCs be controlled for better regional air quality and some key industries should be prior controlled (Http://www.gov.cn /gongbao/content/2010/content_1212364. htm). However, there are few studies about specific industry VOC emission and control strategies [20,21], especially there is a lack of comprehensive studies on different industrial emission sources on a large scale. Most studies have focused on the VOCs emission inventory calculated by the emission factor method which might cause controversy: firstly, most of the emission factors are cited from the databases of other countries without localization, which could result in overestimating the total amount. Secondly, there is no united standard of the industry classification, yielding notable difference among the calculation results. Thirdly, total emission amount calculation could not reveal detailed information like VOCs components and emission level, which are important and useful to the practical VOCs reduction and control.

In this article we report our long term study on industrial VOCs emissions of six typical industries including emission characteristics, environmental impact and health risk assessment, and control challenge analysis with the purpose to explore industry VOCs emissions and offer some original basements for national control and management of industry VOCs emissions.

\section{Methods and experiments}

VOCs are emitted from various industry sources and the selection of typical industry is of importance for the following research work. However, the source information is quite scare and there is no national census on VOCs pollution sources in China. In 2007 similar campaigns were carried out only in Shanghai and Beijing, respectively. Based on preliminary results of 2007 campaigns, vehicle manufacturing (vehicle), furniture manufacturing (furniture), printing, bio-pharming, electronic manufacturing (electronic) and equipment coating (equipment) were selected as the typical industries of VOCs emission. For each industry, several typical enterprises were selected for carrying out on-line VOCs monitoring and measurement at end pipe emission points.

A portable GC-MS (Inficon, USA) is employed for the on-line monitoring and determination of individual VOCs components. Before each measurement, quantity curves were made and methods were edited in the case of different VOC emission level. Other emission parameters like emission temperature, humidity, velocity and so on were also measured by the pollution source sampling device (Tianhong 880F, Wuhan, China). Besides the on-line VOCs monitoring and determination, process investigation was conducted at the same time. The emission amount is calculated by the following formula:

$$
E=K \times \sum C_{i} \times V \times t
$$

where $E$ represents annual emission amount (ton), $K$ refers to the consistent value, $C_{i}$ denotes the determined concentration of individual components $\left(\mathrm{mg} / \mathrm{m}^{3}\right), V$ means emission volume $\left(\mathrm{m}^{3} / \mathrm{h}\right)$ and $t$ refers to annual operation hours.

The material balance method is also used to assessment the VOC potential emission amount:

$$
E=\sum B \times C \times(1-\mathrm{ER})-D \times C,
$$

where $E$ represents potential annual emission amount (ton), $B$ refers to annual solvent usage (ton), $C$ means individual VOCs contents in solvents (\%), $D$ means the recycled solvent per year (ton), and ER means the treatment efficiency. Those data were obtained from on-site survey.

\section{Results and discussion}

\subsection{Industry VOCs emission characteristics from different sources}

Altogether VOCs from six industries were monitored and determined in this campaign, due to the limit of content and page, vehicle manufacturing industry is given as an example to illustrate the individual manufacturing processes related with VOCs emission. According to national statistics, vehicle products increased rapidly in recent years. In 2010 the product number is 18264700 , yielding $32 \%$ increase 
compared with 2009. By now there are more than 120 vehicle manufacturing enterprises distributed in almost every province, and more than half of them mainly deal with auto manufacturing. Typical auto manufacturing processes are given in the following Figure 1.

From Figure 1, it can be seen that VOCs are emitted from three integrated processes: primer coating, intermediate coating and top coating. Among primer coating process, electro-coating method is popularly used and less VOCs are emitted due to the use of waterborne coatings. VOCs are mainly released from intermediate and top coating processes including three key sections [22]: (1) Spraying booth, where the organic solvents are used as dilution and they tend to volatize during the spraying process. Usually the process is characterized by high intensity operation continuously, thus high volume ventilation is introduced, resulting in VOCs emission with middle or low concentrations accompanied by spray smog. (2) Flash-off area. After being sprayed, auto bodies are sent to the flash-off area, where the wet spray film will be formed with uniformity. At the same time, the organic solvents will further evaporate to air without spray smog. Concentrations of VOCs released during this process are about twice of those emitted from the spraying process. Generally, both processes share the same ventilation system, and VOCs determined from the spray process also contain those from the flash-off system. (3) Baking room. After spraying and flashing-off processes, auto bodies are sent to the baking room for further drying at a higher temperature of about $180^{\circ} \mathrm{C}$. Besides the further evaporation in this condition, decomposition and other reactions could also occur due to the high temperature, leading to formation of different VOCs compared with the former two processes. VOCs at this process are usually treated by regenerative thermal oxidation (RTO) technology and yield low emission concentration. VOCs from coating and baking processes in a typical auto manufacturing enterprise are given in Table 1.

From Table 1, it can be seen that different processes yield different VOCs components and the major VOCs components among those processes are benzenes, ketones and esters. Benzenes were detected with the most frequency. The total amount of emitted VOCs from intermediate and top coating is much higher than that from baking process. As we mentioned above, VOCs were mainly yielded during the coating processes at the spraying booth. High emission level of VOCs were also released at the baking room, but they were treated by RTO which shows a removal efficiency $>95 \%$, resulting in low emission level in the end.

Based on the investigation of the selected automobile manufacturing company, it is calculated that the total VOCs

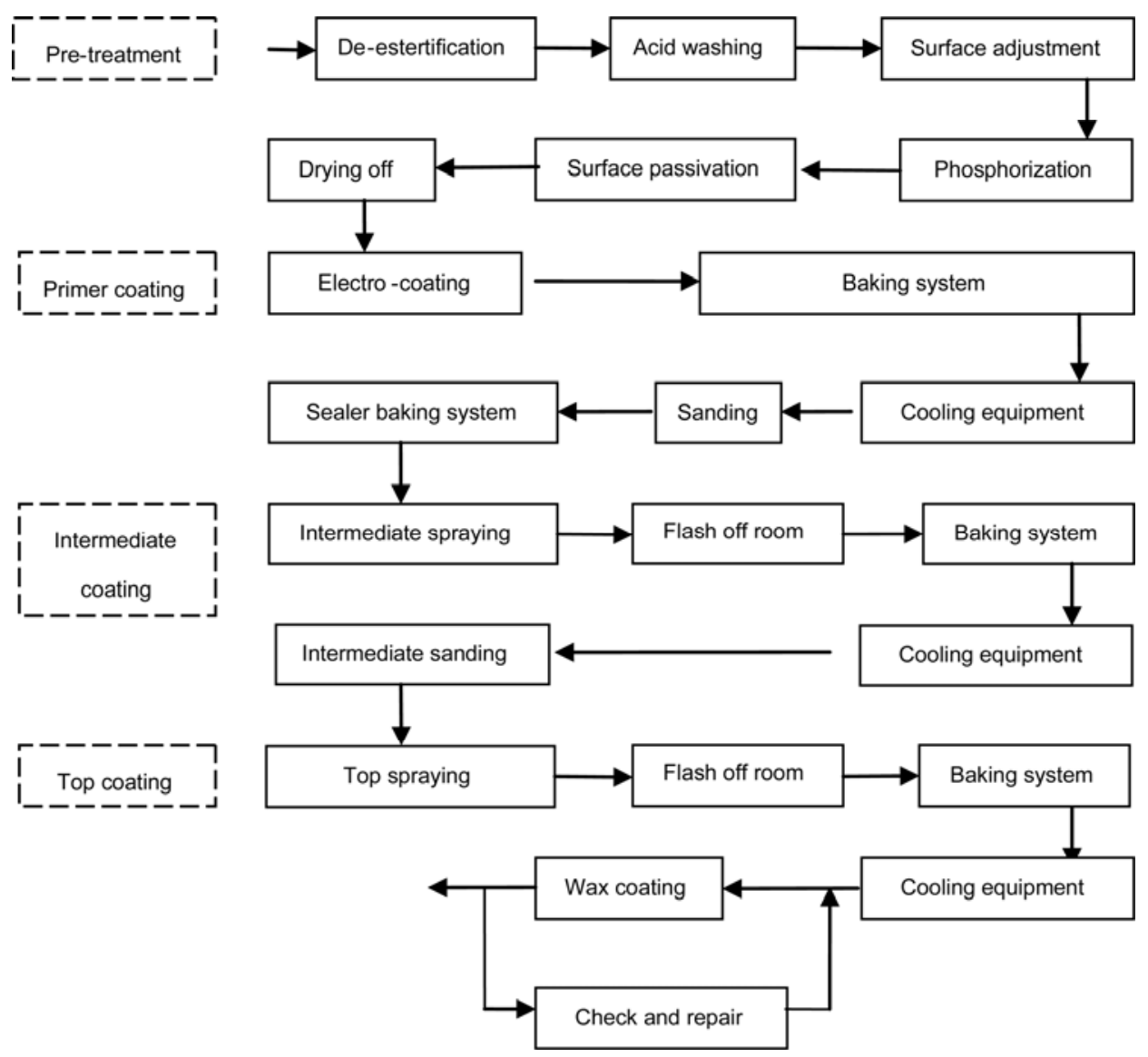

Figure 1 Process flow chart of a typical automobile manufacturing enterprise. 
Table 1 VOCs emissions from different processes in a typical automobile manufacturing enterprise $\left(\mathrm{mg} / \mathrm{m}^{3}\right)$

\begin{tabular}{|c|c|c|c|}
\hline & $\begin{array}{l}\text { Intermediate and top coating } \\
\text { (combined) }\end{array}$ & Top coating (independently) & Baking \\
\hline Isopropanol & 32.14 & - & - \\
\hline 2-Butoxyethanol & 28.45 & - & - \\
\hline Ethylacetate & - & 26.44 & 0.70 \\
\hline Butylacetate & 13.46 & 4.92 & 1.00 \\
\hline 2-Butanone & - & 11.25 & 0.88 \\
\hline 2,3-Butanedione & - & 5.72 & 0.33 \\
\hline Toluene & 6.91 & 20.31 & 3.71 \\
\hline Ethylbenzene & - & 2.95 & - \\
\hline$p$-Xylene & 3.75 & 4.83 & 4.51 \\
\hline$o$-Xylene & 6.09 & 3.28 & 1.13 \\
\hline 1,2,4-Trimethylbenzene & 25.93 & - & 0.36 \\
\hline 1,3,5-Trimethylbenzene & 18.91 & - & - \\
\hline 1-Methyl-4-ethylbenzene & 13.50 & - & 0.21 \\
\hline
\end{tabular}

emission amounts from coating process are about 600 tons and the initial VOCs emission amounts from baking process are about 271 tons. Combined with data from other auto manufacturing companies, we find that coating process is the most important emission section which accounts for $70 \%-90 \%$ of total VOCs emission amounts. Meanwhile, baking process only accounts for $10 \%-30 \%$ of total VOCs emission. An important reason is that VOCs emitted from baking process are treated with high removal efficiency, while VOCs from coating process are directly emitted to atmosphere without treatment.

The actual VOCs emission amounts and the potential VOCs emission amounts are also calculated, which are 686 and 955 ton, respectively. The difference indicates that there is certain VOCs effusion in spite that the whole process was operated in a closed system. It should be noted that the potential in VOCs reduction in auto manufacturing industry is huge if the VOCs treatment of coating process is taken into account. Related data and results of VOCs emission from other industries are listed in Table 2 . It clearly shows that different industries yield different VOCs emission. For a certain industry, different categories also yield different VOCs emission characteristics.

\subsection{Ozone formation potential (OFP) contribution}

The effect of VOCs on atmosphere is tightly related to their chemical reaction activities, which could be assessed by the $\mathrm{OFP}$ and $\mathrm{OH}$ loss rates $\left(L_{\mathrm{OH}}\right)$. Both provide ways to calculate VOCs' contribution to ozone formation [23,24]. $L_{\mathrm{OH}}$ method needs the detailed information of atmospheric intermediate reaction steps and some researchers found that the $L_{\mathrm{OH}}$ method could underestimate VOCs' contribution to ozone formation [25]. While, OFP method could reflect the VOCs' contribution when only VOCs data are available.
Therefore, the OFP method is used in this study.

$$
\mathrm{OFP}=\sum \mathrm{MIR} \times C_{i},
$$

where $C_{i}$ denotes the determined VOCs concentrations in these industries, MIR is defined as the maximum incremental reactivity of individual VOCs and the specific MIR values are cited from carter's study [26], OFP calculated results are shown in Figure 2.

OFP values of VOCs from the determined six industries are in the following order: vehicle $>$ equipment $>$ furniture $>$ printing $>$ electronics $>$ bio-pharming. Vehicle manufacturing shows that the highest OFP values, which are mainly related to the higher VOCs emission level and more individual components detected. Electronics gives the second lowest OFP values due to the end treatment with high efficiency. Bio-pharming yields the lowest OFP value, the reason is that ethanol is the dominated component and its MIR value is relatively low. For different kinds of VOCs, the OFP contribution is in the following order: benzenes $>$ esters $>$ alcohols $>$ ketones $>$ alkenes $>$ chloroalkanes. Although the MIR values of benzenes are not the highest, the

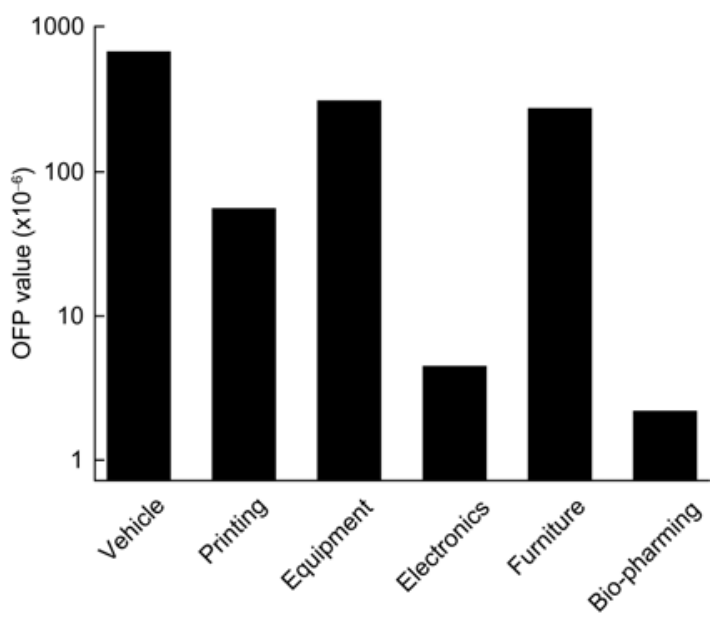

Figure 2 OFP contribution of VOCs from six industry emissions. 
Table 2 Summary of VOCs emission from typical industries

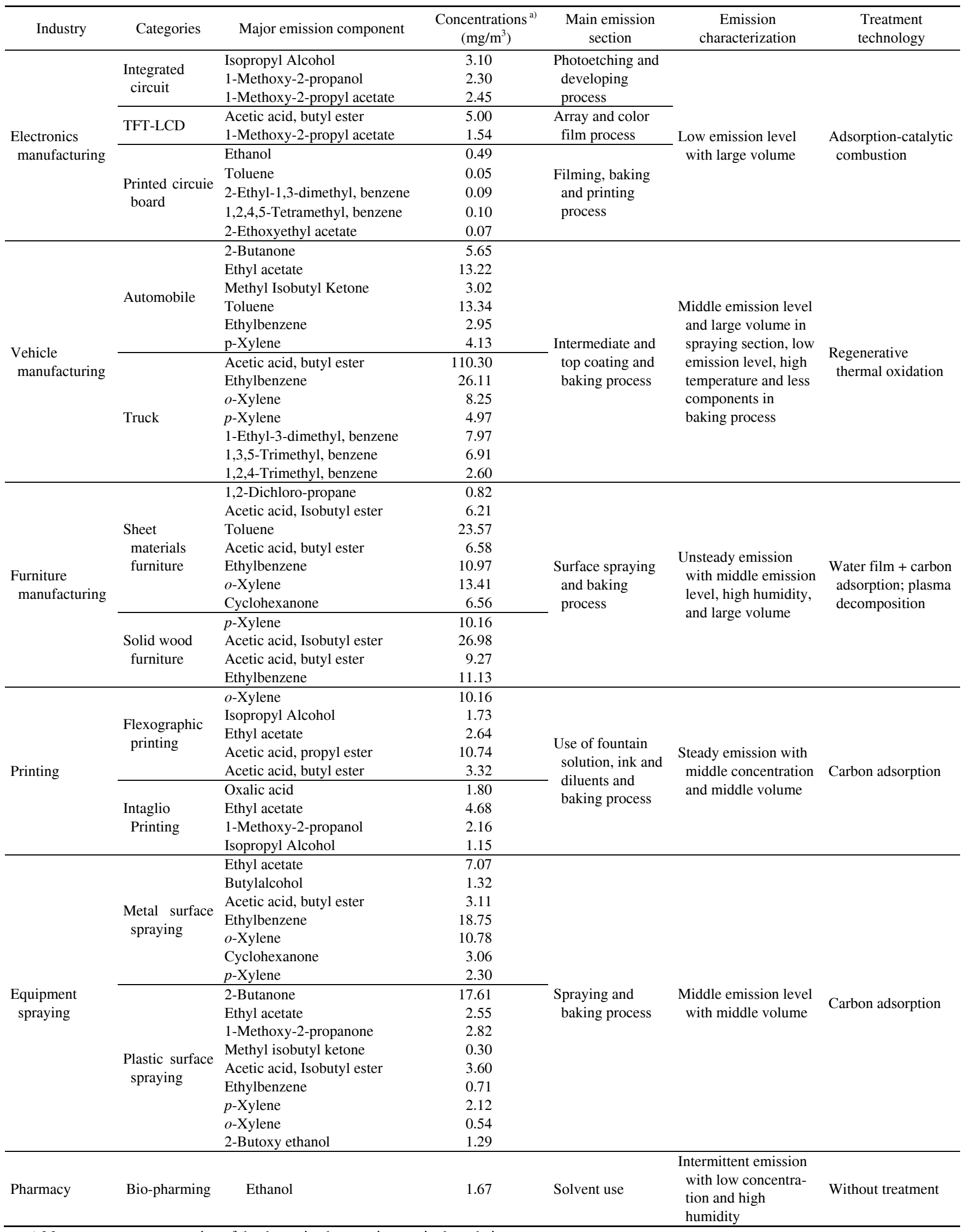

a) Means average concentration of the determined enterprises at single end pipe. 
high emission levels result in the largest ozone formation contribution, which accounts for about $64 \%$ of total OFP of VOCs.

\subsection{Health risk assessment (HRA) of industry VOCs}

An internationally recognized four-step evaluation model of HRA is adapted to preliminarily assess the health risk caused by industry VOCs emission, the receptors of interest are production line workers in the selected industries and the main exposure route line is inhalation. The inhalation intakes (CDI) used for HRA were calculated as following

$$
\mathrm{CDI}=\left(C_{i} \times \mathrm{IR} \times \mathrm{ED} \times \mathrm{EF}\right) /(\mathrm{BW} \times \mathrm{AL}),
$$

where $C_{i}$ denotes the exposure concentration, here it is assumed that the exposure concentration is close to the end emission level. Exposure duration (ED) and exposure frequency $(\mathrm{EF})$ were obtained by on-site investigation. Other parameters including inhalation rate (IR), body weight (BW) and average life (AL) were obtained from reference [27]. HRA usually includes carcinogenic risk and non-carcinogenic risk assessments. Considering that the most reference values used for carcinogenic risk calculation are incomplete, HRA here mainly refers to non-carcinogenic risk assessment. According to the research [28], non-carcinogenic risk assessment accounts for a large percent of HRA, and it is usually characterized by HI (hazard index), which could be calculated by following the reference method [28]. The calculated $\sum$ HIi values are shown in Figure 3.

$\sum$ HIi values of the determined six industries are in the following order: furniture $>$ vehicle $>$ equipment $>$ printing $>$ electronics $>$ bio-pharming. Furniture manufacturing industry shows the highest $\sum$ HIi values which are related to chloroalkanes like 1,2-dichloroprpane besides the high VOCs emission level, and the chloroalkanes account for $55 \%$ of $\sum$ HIi value in the furniture manufacturing industry. Compared with other industries, furniture manufacturing industry depends more on manual operation, which means more exposure frequency and longer exposure time for the production line workers. So, from the health protection

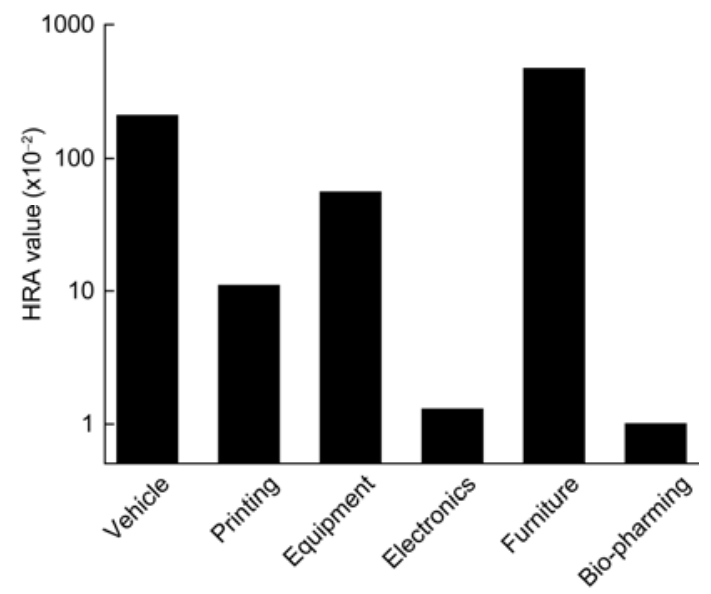

Figure 3 HRA results of VOCs from six industry emissions. point of view, furniture manufacturing industry should be prior controlled and VOCs emission should be well treated.

\subsection{Control challenge analysis of industry VOCs emission}

Industry VOCs emission should be controlled due to their direct impacts on atmosphere and human health, but how to carry out emission control is the major challenge at present stage in China. Technology treatment is an efficient way for VOCs emission reduction. Technology control measures include source reduction and end pipe emission treatments, and currently more focuses are placed on the later. End pipe emission treatments include adsorption, catalytic incineration, condensation, bio-degradation, plasma decomposition and so on. The major technologies for industry VOCs treatment in China are adsorption, catalytic incineration and adsorption incineration and each has its own advantages and disadvantages [29]. As estimated, the percent of being-treated enterprises is less than $10 \%$ [30]. The common problems lie in high cost of investment and operation and not so satisfied treated performances due to the complex emission condition. Therefore, it is necessary to develop low-cost and combined technologies for industry VOCs emission control.

Besides the end pipe treatment, administration and supervision are also the important and efficient measures for VOCs emission control, which are usually carried out based on the emission standards and regulations. However, in China VOCs have started to be considered as major air pollutants and attracted significant attention in recent years. Established national emission standards involve coking, catering, gas station, synthetic leather industries, and only 9 specific components and 3 integrated targets are included and the summary of the existing national standards in China is given elsewhere [31]. The deficiency of industrial emission standards and regulations fails to meet the requirement of administration and supervision. Hence, it is necessary and urgent to establish more specific industry VOCs emission standards and regulations and update those old ones.

Compared with the standard/regulation and technology control, environmental economic measure provides another efficient way to control VOCs emission. As an important part, emission charge system has unique advantages in VOCs control and management: firstly, it will reduce the VOCs treatment cost for the enterprises to maximize the profit. Secondly, the charge system will stimulate the enterprises to be environment friendly in a long term. Thirdly, charge system offers flexible selections for both authorities and enterprises. Taiwan sets an excellent example at this field [32], and our preliminarily study also indicates imposing environmental tax on high emission sectors could decrease the VOCs total emission amount considerably [33]. 


\section{Conclusions}

VOCs from typical manufacturing industries including vehicle, furniture, electrics, equipment, bio-pharming and printing were studied by combining process investigation and end pipe on-line monitoring in this article. Seven kinds of VOCs including benzenes, alcohols, esters, ketones, chloroalkanes, and alanes and more than 60 principal individual components were detected. VOCs from industrial end pipe emission are characterized by middle and low concentration together with high emission volume, and vary with responding to different industries and different processes even at the same industry. From the air pollution control point of view, vehicle manufacturing and benzenes should be controlled as the prior industry and prior pollutants, respectively. While, from the human health protection point of view, furniture manufacturing industry and chloroalkanes should be prior controlled. The main challenges for industry VOCs emission control are not only the technology problems, but also the deficiency in VOCs emission standards and regulations for specific industries.

This work was supported by the Team Interaction and Cooperation of the Science and Technology Program of the Chinese Academy of Sciences, the Knowledge Innovation Program of the Chinese Academy of Sciences (KZCX2-YW-JS402), the National Basic Research Program of China (2010CB732300), the Strategic Priority Research Program of the Chinese Academy of Science (XDB05050200), the National High Technology Research and Development Program of China (2012AA063101), the Program of Chinese Academy for Environmental Planning (2012A014) and Beijing Municipal Natural Science Foundation (8112015).

1 Emission standards of air pollutants for petroleum refining and petrochemicals manufacturing industry (in Chinese). DB11/447-2007

2 Integrated emission standards of air pollutants (in Chinese). DB11/ 501-2007

3 Emission standard of pollutants for synthetic leather and artificial leather industry (in Chinese). GB21902-2008

4 Guenther A, Hewitt C, Erickson D, et al. A global model of natural volatile organic compound emissions. J Geophys Res, 1995, 100: 8873-8892

5 Picot S D, Watson J J, Jones J W. A global inventory of volatile organic compound emissions from anthropogenic sources. J Geophys Res, 1992, 97: 9897-9912

6 Tie X X, Li G H, Ying Z M, et al. Biogenic emissions of isoprenoids and NO in China and comparison to anthropogenic emissions. Sci Total Environ, 2006, 371: 238-251

7 Klimont Z, Streets D G, Gupta S, et al. Anthropogenic emissions of non-methane volatile organic compounds in China. Atmos Environ, 2002, 36: 1309-1322

8 Klinger L F, Li Q J, Guenther A, et al. Assessment of volatile organic compound emissions from ecosystems of China. J Geophys Res, 2002, 107: 4603-4624

9 Wang Z H, Bai Y H. A biogenic volatile organic compounds emission inventory for Beijing. Atmos Environ, 2003, 37: 37713782

10 Liu J F, Zhao J, Li T T, et al. Establishment of Chinese anthropogen- ic source volatile organic compounds emission inventory (in Chinese). China Environ Sci, 2008, 28: 496-500

11 Wei W, Wang S X, Chatani S, et al. Emission and speciation of non-methane volatile organic compounds from anthropogenic sources in China. Atmos Environ, 2008, 42: 4976-4988

12 US Environmental Protection Agency (1999) Integrated Risk Information System (IRIS) on Chlorobenzene. National Center for Environmental Assessment, Office of Research and Development

13 US Environmental Protection Agency (1995) Chlorobenzene Chemical Fact Sheet. OPPT Chemical Fact Sheets. Accessed online Jan, 1995: Http://www.epa.gov/chemfact/chlor-sd. pdf

14 Von B R. Toxicology updates, Monochlorobenzene. J Appl Toxicol, 1981, 1: 50-51

15 Roth B, Herkenrath P, Lehmann H, et al. DEHP as plasticizer in PVC respiratory tubing systems: indications of hazardous effects on pulmonary function in mechanically ventilated, preterm infants. Eur $\mathbf{J}$ Pediatr, 1988, 147: 41-46

16 Li F S. Influence on health status of workers exposed to benzene (in Chinese). Occupation Health, 2008, 17: 1760-1762

17 Geng F, Tie X X, Xu J M, et al. Characterizations of ozone, $\mathrm{NO}_{x}$ and VOCs measured in Shanghai, China. Atmos Environ, 2008, 42: 6873-6883

18 Zhang Y H, Su H, Zhong L J, et al. Regional ozone pollution and observation-based approach for analyzing ozone-precursor relationship during the PRIDE-PRD2004 campaign. Atmos Environ, 2008, 42: 6203-6218

19 Shao M, Zhang Y H, Zeng L M, et al. Ground-level ozone in the Pearl River Delta and the roles of VOCs and $\mathrm{NO}_{x}$ in its production. $\mathrm{J}$ Environ Manag, 2009, 290: 512-518

20 Xu J, Wei H P, Xiu G L. A study on emission pattern of volatile organic compounds (VOCs) from semiconductor manufacturing industry (in Chinese). Shanghai Envion Sci, 2007, 26: 198-206

21 Jia $\mathrm{J} \mathrm{H}$, Huang $\mathrm{C}$, Chen $\mathrm{C} \mathrm{H}$, et al. Emission characterization and ambient chemical reactivity of volatile organic compounds (VOCs) from coking processes. Acta Sci Circumst, 2009, 29: 905-912

22 CAEPI. Selection and assessment of treatment technologies for VOCs pollution in Beijing. BJEPB Technical Report. 2012

23 Atkinson R, Arey J. Atmospheric degradation of volatile organic compounds. Chem Rev, 2003, 103: 4605-4638

24 Huang S, Shao M, Lu S H, et al. Reactivity of ambient volatile organic compounds(VOCs) in summer of 2004 in Beijing (in Chinese). Chin Chem Lett, 2008, 19: 573-576

25 Luo W, Wang B G, Liu S L, et al. VOC ozone formation potential and emission sources in the atmosphere of Guangzhou (in Chinese). Environ Sci Technol, 2011, 34: 80-86

26 Carter W P L. Development of ozone reactivity scales for volatile organic compounds. J Air Waste Manag Assoc, 1994, 44: 881-899

27 USEPA. EPA/540/1-89/002. Office of Emergency and Remedical Response, Washington DC, 1989

28 Zhou Y M, Hao Z P, Wang H L. Health risk assessment of atmospheric volatile compounds in urban-rural juncture belt area (in Chinese). Environ Sci, 2011, 32: 3566-3570

29 Luan Z Q, Hao Z P, Wang X Q. Evalution of treatment technology of volatile organic compounds for fixed industrial resources (in Chinese). Environ Sci, 2011, 32: 3476-3486

30 Hao Z P, Luan Z Q. Report on Environmental Protection Technology. Beijing: China Environmental Sciences Press, 2009. 58-63

31 Wang H L, Zhang G N, Hao Z P, et al. Study on control and management for industrial volatile organic compounds(VOCs) in China (in Chinese). Environ Sci, 2011, 42: 3462-3468

32 Luan Z Q, Wang X Q, Zheng Y N, et al. Regulations and policies for control of volatile organic compounds and the emission standards in Taiwan (in Chinese). Environ Sci, 2011, 42: 3491-3500

33 Liu C X, Wang Y F, Wang H L, et al. VOCs tax policy on China's economy development (in Chinese). Environ Sci, 2011, 42: 3501-3508

Open Access This article is distributed under the terms of the Creative Commons Attribution License which permits any use, distribution, and reproduction in any medium, provided the original author(s) and source are credited. 